Research Article

\title{
Body mass index values for term newborns and its correlation with other anthropometric surrogates
}

\author{
Rugmini Kamalammal $^{1}$, Soorya Rao $^{2}$, P. J. Parameaswari ${ }^{3}$
}

\begin{abstract}
${ }^{1}$ Department of Pediatrics, Adichuchanagiri Institute of Medical Sciences, B G Nagara, Mandya, Karnataka, India ${ }^{2}$ Department of ENT, Adichuchanagiri Institute of Medical Sciences, B G Nagara, Mandya, Karnataka, India ${ }^{3}$ Biostatistician, Crea Conceptions Counselling and Training Center, Center for Assisted Reproduction, Habibullah Road, T Nagar, Chennai, India
\end{abstract}

Received: 03 October 2015

Revised: 07 October 2015

Accepted: 14 November 2015

\section{*Correspondence:}

Dr. Rugmini Kamalammal,

E-mail: rugminirao@yahoo.com

Copyright: $@$ the author(s), publisher and licensee Medip Academy. This is an open-access article distributed under the terms of the Creative Commons Attribution Non-Commercial License, which permits unrestricted non-commercial use, distribution, and reproduction in any medium, provided the original work is properly cited.

\section{ABSTRACT}

Background: Body mass index is a better tool as it relates two anthropometric measures - Weight and Length. This study aims at identifying the mean BMI in term new-borns in Asian population and also the correlation between BMI and other anthropometric surrogates for birth weight.

Methods: Cross Sectional study was conducted in a tertiary care hospital by taking anthropometric measurements for 339 consecutive term newborns, born in the institution. Mean BMI was $11.784 \pm 1.7$. Moderate Positive correlation was observed between BMI and Mid Arm Circumference ( $r=+0.401 ; \mathrm{P}=0.000)$.

Results: The cut off value for BMI to identify LBW was 13. Mid Arm Circumference, Chest circumference and Head circumference correlated well with BMI.

Conclusions: By trial and error method of analysis we recommend BMI value of 13 as a cut off for identifying low birth weight infants. BMI is seen to be better than Birth weight in assessing body proportion of a new born.

Keywords: Body mass index, Birth weight, Anthropometric surrogates

\section{INTRODUCTION}

Incidence of low birth weight in developing countries $(16.5 \%)$ is more than double the level in developed regions i.e. $7 \% .^{1}$ Forty percent of all LBW babies in the developing world are born in India. ${ }^{2}$ It is associated with increased morbidity and mortality.

Birth weight is the basic criteria by which nutrition is accessed in a newborn till date. BMI which is derived from the two anthropometric measurements is probably considered to be better assessment criteria. ${ }^{3}$ The Body mass index (BMI), which is a measure of adiposity in children and adults, is used as a measure of nutrition also. The same can be applied to the neonates also.

There are various studies done earlier, which looked into the correlation between birth weight and other anthropometric surrogates. These studies showed that the Mid Arm circumference, Chest circumference and head circumference correlated well with birth weight. ${ }^{4-14}$

A study done by Brock RS, charted BMI for newborns according to the gestational age and the mean BMI in term neonates were found to be $13.25 \pm 1.11$. $^{15}$ It also validated BMI as a good tool for accessing nutrition. This study was done in Caucasian population and hence the 
BMI value may be slightly high when compared to Asian population. Mean BMI observed in another study done in South India was $12.86 \mathrm{~kg} / \mathrm{m}^{2}$ close to the expected value of $13 .{ }^{8}$ In addition, this study showed good correlation with BMI and Mid Arm Circumference.

In these circumstances, the purpose of the present study was to determine the mean BMI for South Asian population and to recommend a cut off value for BMI for identifying LBW. In addition, the study determines the correlation of various anthropometric surrogates with BMI. The present study was conducted with the written informed consent from the parents after clearance from the Institutional Research and Ethics Committee.

\section{METHODS}

All full-term, singleton, live born babies born of consecutive deliveries $(n=339)$ that took place from June 2012 to Feb 2013 were included in this study. One of the investigators examined all the neonates, assessed gestational age and measured anthropometric measurements within 24 hours of birth. Only those who are greater than 37 weeks of gestational age were enrolled in the study. The neonates with congenital anomalies/ dysmorphic features were excluded.

Anthropometric measurements taken were birth weight (BW), Length, Mid Arm Circumference (MAC), Chest circumference (CC) and Head circumference (HC).

All the neonates were weighed on a spring type of weighing scale to the nearest 50 grams. Standardizations of the weighing machine were done daily. The length, in centimetres, was obtained with the newborn in the supine position, on a rigid surface, using an Infantometer, with the aid of another person to hold the infant. Other measurements were made with a non-stretch plastic measuring tape. Mid-upper Arm circumference (MAC) was measured at the midpoint between the tip of Acromion process and Olecranon process of the left upper arm. Chest Circumference (CHC) was measured at the level of nipple at the end phase of expiration. Head Circumference (HC) was measured between Glabella and the most prominent point of Occiput posteriorly.

\section{RESULTS}

In the present study of 339 newborns, 178 (52.5\%) were males and $161(47.5 \%)$ females. Mean Birth weight was found to be $2.9 \pm 0.02 \mathrm{~kg}$ (birth weight was ranging from $1.5 \mathrm{~kg}$ to $3.9 \mathrm{~kg}$ ). The percentage of $\mathrm{LBW}$ infants was $11.8 \%$; Head circumference ranges from 30 to $37 \mathrm{~cm}$ with Mean \pm SE as 33.0 \pm 0.07 ; Chest circumference from 27 to $37 \mathrm{~cm}$ with mean $31.8 \pm 0.09$; Mid Arm circumference from $8 \mathrm{~cm}$ to $13 \mathrm{~cm}$ with mean $9.92 \pm 0.05$.

The mean BMI was $11.7 \pm 1.7 \mathrm{~kg} / \mathrm{m}^{2}$. The mean BMI for males was $11.8 \pm 1.6 \mathrm{~kg} / \mathrm{m}^{2}$ and that for females was
$11.7 \pm 1.8 \mathrm{~kg} / \mathrm{m}^{2}$. This difference was statistically insignificant with a $\mathrm{P}=0.36$

We also observed a positive correlation of ' $\mathrm{r}=+0.56(\mathrm{P}=0.000)$ ' for MAC with Birth weight and ' $\mathrm{r}=+0.556(\mathrm{P}=0.000)$ ' for MAC with $\mathrm{CC}$. A significant mild positive correlation was seen among $\mathrm{HC}$ with $\mathrm{CC}$ and $\mathrm{BW}, \mathrm{CC}$ with $\mathrm{BW}$ respectively.

Student-t-test in Table 1 shows a statistically significant difference in the BMI values between the groups in $\mathrm{HC}$, $\mathrm{CC}$ and MAC. Since Length and Birth Weight were used to estimate BMI, we calculated Karl Pearson's Bivariate Coefficient of Correlation between $\mathrm{HC}, \mathrm{CC}, \mathrm{MAC}$ and BMI.

Table 1: Student -t-test of BMI for anthropometric measures.

\begin{tabular}{|llll|}
\hline $\begin{array}{l}\text { Measures } \\
(\mathrm{cm})\end{array}$ & $\mathbf{N}$ & $\begin{array}{l}\text { Mean } \pm \text { SE } \\
(\text { Mean })\end{array}$ & $\begin{array}{l}\text { t-value } \\
\text { (P-value) }\end{array}$ \\
\hline $\mathrm{HC} \leq 32.5$ & 117 & $11.2 \pm 0.14$ & 3.945 \\
$\mathrm{HC}>32.5$ & 220 & $12.0 \pm 0.12$ & $(0.000)^{*}$ \\
\hline $\mathrm{CC} \leq 30.5$ & 52 & $11.3 \pm 0.25$ & 1.998 \\
$\mathrm{CC}>30.5$ & 287 & $11.8 \pm 0.10$ & $(0.047)^{*}$ \\
\hline $\mathrm{MAC} \leq 9$ & 98 & $11.1 \pm 0.18$ & 4.401 \\
$\mathrm{MAC}>9$ & 241 & $12.0 \pm 0.10$ & $(0.000)^{*}$ \\
\hline
\end{tabular}

*Significant; HC-Head circumference; CC-chest circumference; MAC-Mid arm circumference.

Figure 1 shows the Scatter plot and there existed a Statistically Significant positive High Correlation of these measures with $\mathrm{BMI}(\mathrm{P}=0.000)$.

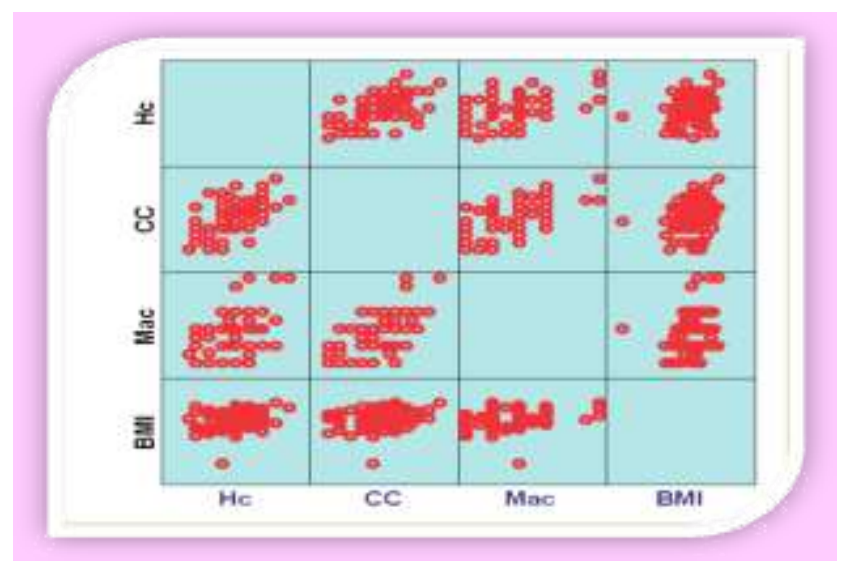

Figure 1: Scatter plot of anthropometric measures with BMI.

Table 2 presents the sensitivity, specificity for three anthropometric measures at different BMI levels i.e. 11, 12 and 13 by trial and error method. ROC curves from Figure 2 highlights a good coordinates for these measures which is similar to the other studies of BMI 13. Hence, as per Kapoor SK et al, Naik DB et al and Brock RS et al, we have grouped the BMI at 13, we observed 257 (75.8) 
with $\mathrm{BMI} \leq 13,82(24.2)$ with $\mathrm{BMI} \geq 13$. Among them 148 (43.7) males and 109 (32.2) females had $\mathrm{BMI} \leq 13$; $30(8.8)$ males and 52(15.3) females had $\mathrm{BMI} \geq 13$. ${ }^{13-15}$

Figure 3 Shows Error Bars for HC, CC and MAC. There was Statistically Significant Association between the BMI 13 group with HC $\quad\left[\chi^{2}=24.07(\mathrm{P}=0.000)\right]$ and MAC $\left[\chi^{2}=14.7(\mathrm{P}=0.000)\right]$ contributing to 3.7 times chance of identifying the LBW babies [odds ratio=3.7(1.8 to7.6)] and an insignificant association was observed with $\mathrm{CC}$.

The main findings of our study: BMI correlates well with $\mathrm{HC}, \mathrm{CC}, \mathrm{MAC}$ and it is better than Birth weight in assessing the newborn nutrition. BMI 13 is the ideal cutoff point in identifying the LBW newborns.

Table 2: Cut off points of anthropometric measures for different BMI.

\begin{tabular}{|c|c|c|c|}
\hline BMI & $\begin{array}{l}\text { Measures } \\
(\mathrm{cm})\end{array}$ & $\begin{array}{l}\text { Sensitivity } \\
(\%)\end{array}$ & $\begin{array}{l}1 \text {-Specificity } \\
(\%)\end{array}$ \\
\hline \multirow{3}{*}{11} & HC - 29.75 & 99.1 & 100 \\
\hline & CC -26.00 & 97.7 & 99.2 \\
\hline & MAC - 8.25 & 94.8 & 91.3 \\
\hline \multirow{3}{*}{12} & $\mathrm{HC}-29.75$ & 97.1 & 99.0 \\
\hline & CC - 27.5 & 97.8 & 98.5 \\
\hline & MAC - 8.55 & 93.4 & 91.6 \\
\hline \multirow{3}{*}{13} & $\mathrm{HC}-30.5$ & 95.1 & 95.3 \\
\hline & CC - 28.5 & 97.6 & 91.4 \\
\hline & MAC - 8.80 & 90.0 & 89.1 \\
\hline
\end{tabular}

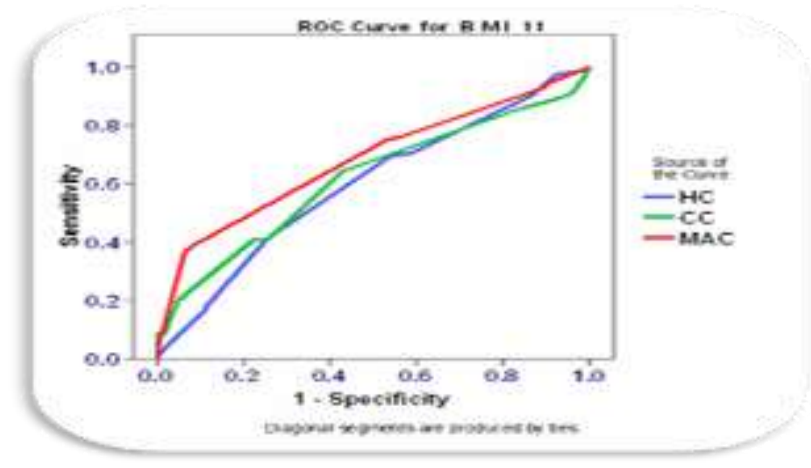

Figure 2A: ROC curve for BMI 11.

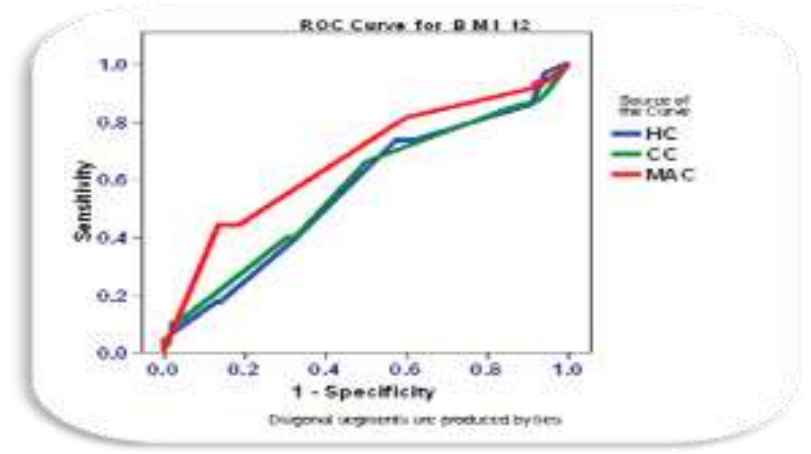

Figure 2B: ROC curve for BMI 12.

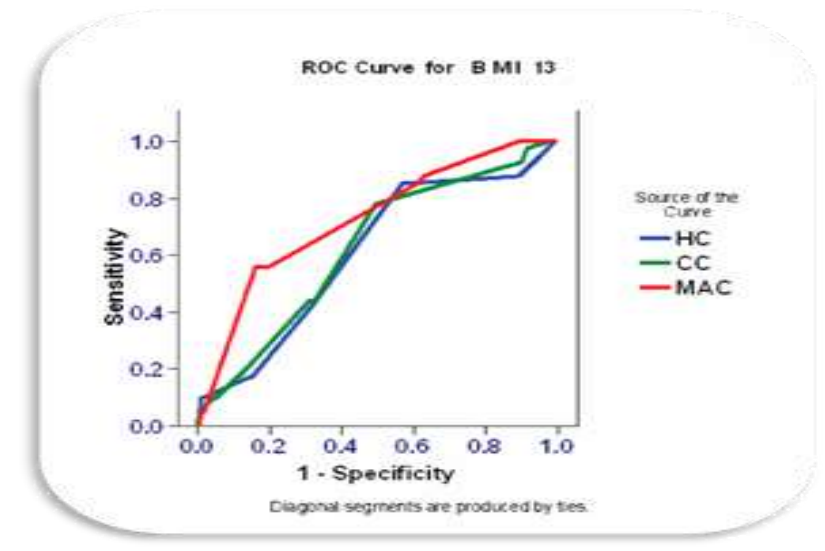

Figure 2C: ROC curve for BMI 13.

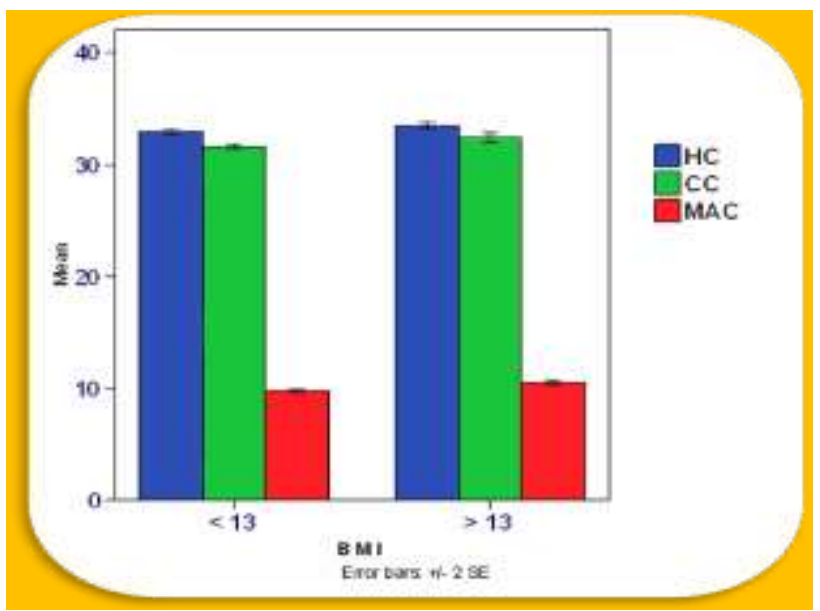

Figure 3: Anthropometric measures for BMI 13.

\section{DISCUSSION}

Our study showed mean birth weight of the newborns as $2.9 \pm 0.02 \mathrm{~kg}$ which is comparable with WHO criteria for this region. But the WHO standard for average birth weight in the world is $3.229 \mathrm{~kg}$. ${ }^{1}$ The average BMI of $11.87 \mathrm{~kg} / \mathrm{m}^{2}$ for term neonate was close to the value of $12.86 \mathrm{~kg} / \mathrm{m}^{2}$ arrived in the previous study done in South India 8 but less when compared with Brazil study. ${ }^{15}$ The comprehensive study done in a large population in Brazil has shown a value of $13.25 \pm 1.11 \mathrm{~kg} / \mathrm{m}^{2}$ at 37 weeks and $14.10 \pm 1.01$ at 40 weeks. Our study had only $24.2 \%$ of babies with $\mathrm{BMI} \leq 13$. This may be due to the fact that our hospital caters to lower middle class population and when compared to western standards the mean Birth weight was low. Moreover, this variation can be explained by the difference in the population studies as Caucasians are proved to have a better BMI due to the genetic variation. Another contributing factor may be the significantly higher percentage of Low Birth Weight babies in our population.

The BMI showed no significant statistical difference between males and females in our study which is in 
agreement with study done in Brazil where no difference was noted in almost all the gestational ages. ${ }^{15}$

BMI was analyzed for correlation with three parameters i.e. MAC, $\mathrm{HC}$ and $\mathrm{CC}$ which will give us an indirect way to assess whether BMI alone is sufficient to assess the neonatal nutrition. On the other hand it will also give us an idea which of the parameters can be used as a surrogate for BMI in the community. This has got prime importance as in the community there are some logistic deficits which leads to not weighing the newborn at birth. In these situations surrogates can come to use to identify low birth weight babies who need special care.

BMI has shown better correlation with all surrogates taken. High Significant Correlation was seen with MAC, but others like $\mathrm{CC}, \mathrm{HC}$ was also moderately significant. This fact was already suggested in a study where correlation with MAC and BMI was established. ${ }^{8}$ Much more studies are to be conducted to find out the correlation with BMI and these surrogates mentioned above. Studies are lacking in this particular area even though many studies are there showing correlation with birth weight. ${ }^{4-14}$

We trialed the BMI cutoff points at 11, 12, 13 for the anthropometric surrogates and compared their efficacy as provided in Table 2. This was done with proof from other studies, where their mean BMI ranged from 11 to 13.

Our own previous studies have shown a cut off value of $8.55 \mathrm{~cm}$ for MAC in low birth weight babies who had a sensitivity of $90 \%$ and specificity of $95.3 \%$ which is a good criteria for a screening tool in identifying low birth weight babies. Cutoff given for mid arm circumference by other studies ranges from $8.44 \mathrm{~cm}$ to $9 \mathrm{~cm}$. This study also gives a cut off value 8.25 and 8.55 for BMI 11 and 12. Head circumference did not show much difference with various BMI, which can be due to the sparing of growth retardation of head in cases of IUGR babies.

In our study the cut off for LBW in terms of BMI was 13 with sensitivity $90 \%$ and Specificity $95 \%$. This low cut off is good enough for the community where the study was done as the nutrition of new born is low when compared to western standards. This low cut off aids in maximal referral and special care being given to all babies who require the same. In other words, it reduces the false negatives.

To our surprise chest circumference showed a satisfactory significant correlation with birth weight. It is suggested as best surrogate by other studies. ${ }^{5,12,13}$

\section{CONCLUSION}

BMI is a better tool to assess neonatal nutrition. The Effective cut off for identifying Low Birth Weight babies is $13 \mathrm{~kg} / \mathrm{m}^{2}$. Average BMI at neonatal period for South Indian population can be suggested as -13 . Assessment of nutrition at newborn period itself helps to provide a baseline value for further follow up and also reflects intra uterine growth. To present BMI as a good tool, further studies with large sample size should be conducted in the developing countries and also in the same ethnic group.

Funding: No funding sources

Conflict of interest: None declared

Ethical approval: The study was approved by the Institutional Ethics Committee

\section{REFERENCES}

1. Blanc AK, Wardlow T. Monitoring low birth weight: an evaluation of international estimates and an update estimation procedure. Bull world heal organization. 2005;83:178-85.

2. UNICEF: Progress for children. A report card on nutrition. 2006;4:10-1.

3. Caiza SME, Díaz RJL, Simini F. Ponderal index to describe a term neonatal population. An Pediatr (Barc). 2003;59:48-53.

4. Use of a Simple Anthropometric Measurement to Predict Birth Weight. Academic journal article. Bulletin of the World Health Organization. 1993;71(2):157-63.

5. Kaur H, Bansal R .Anthropometric determinants of low birth weight in newborns of Hoshiarpur district (Punjab) - A hospital based study. Human Biology Review. 2012;1(4):376-86.

6. Figueira BBD, Segre CAM. Mid-arm circumference and mid-arm/head circumference ratio in term newborns. Sao Paulo Med J. 2004;122(2):53-9.

7. Das JC, Afroze A, Khanam ST, Paul N. Mid-arm circumference: an alternative measure for screening low birth weight babies. Bangladesh Med Res Counc Bull. 2005;31:1-6.

8. Bindu NR, Elizabeth KE, Geetha S, Sarath V. Mid Arm Circumference (MAC) and Body Mass Index (BMI) - The Two Important Auxologic Parameters in Neonates . Journal of Tropical Pediatrics. 2006;52(5):341-5.

9. Kadam YR, Somaiya P, Kakade SV. A Study of Surrogate Parameters of Birth Weight. Indian J Community Med. 2005;30:89-91.

10. Rustagi N, Prasuna JG, Taneja DK. Anthropometric surrogates for screening of low birth weight newborns: a community-based study. Asia Pac J Public Health. 2012;24(2):343-51.

11. Sreeramareddy CT, Chuni N, Patil R, Singh D, Shakya B. Anthropometric surrogates to identify low birth weight Nepalese newborns: a hospitalbased study. BMC Pediatrics. 2008;8:16.

12. Elizabeth NL, Christopher OG, Patrick K. Determining an anthropometric surrogate measure for identifying low birth weight babies in Uganda: a hospital-based cross sectional study. BMC Pediatrics. 2013;13:54.

13. Kapoor SK, Kumar G, Anand K. Use of mid-arm and chest circumferences to predict birth weight in 
rural north India. J Epidemiol Community Health. 1996;50(6):683-6.

14. Naik DB, Kulkarni AP, Aswar NR. Birth weight and anthropometry of newborns. The Indian Journal of Pediatrics. 2003;70(2):145-6.

15. Brock RS, Falcão MC, Leone C. Body mass index values for newborns according to gestational age. Nutr Hosp. 2008;23(5):487-92.
Cite this article as: Kamalammal $\mathrm{R}$, Rao $\mathrm{S}$,

Parameaswari PJ. Body mass index values for term newborns and its correlation with other anthropometric surrogates. Int J Contemp Pediatr 2016;3:120-4. 